\title{
A Novel Method of Synthesizing Graphene for Electronic Device Applications
}

\author{
Nierlly Galvão ${ }^{1, *}$, Getúlio Vasconcelos ${ }^{2}$, Rodrigo Pessoa 1,3,*(D), João Machado ${ }^{4}$, Marciel Guerino ${ }^{1}$, \\ Mariana Fraga ${ }^{3}$ (D), Bruno Rodrigues ${ }^{1,3}$, Julien Camus ${ }^{5}$, Abdou Djouadi ${ }^{5}$ and Homero Maciel ${ }^{1,3}$ \\ 1 Centro de Ciência e Tecnologia de Plasmas e Materiais-PlasMat, Instituto Tecnológico de Aeronáutica, \\ 12228-900 São José dos Campos, SP, Brazil; marcielguerino@yahoo.com.br (M.G.); \\ bruno.manzolli@gmail.com (B.R.); homero@ita.br (H.M.) \\ 2 Photonics Division, Instituto de Estudos Avançados, Rodovia dos Tamoios, \\ 12228-001 São Jose dos Campos, SP, Brazil; getulio@ieav.cta.br \\ 3 Universidade Brasil, Rua Carolina Fonseca 235, 08230-030 São Paulo, SP, Brazil; mafraga07@hotmail.com \\ 4 Associate Laboratory of Sensors and Materials, Instituto Nacional de Pesquisas Espaciais, \\ 12227-010, São José dos Campos, SP, Brazil; machadopaulo@gmail.com \\ 5 Institut des Matériaux Jean Rouxel IMN, UMR 6502, Université de Nantes, 2 rue de La Houssinière, \\ BP 32229, Nantes Cedex 44322, France; julien.camus@cnrs-imn.fr (J.C.); abdou.djouadi@cnrs-imn.fr (A.D.) \\ * Correspondence: nierlly@gmail.com (N.G.); rspessoa@ita.br (R.P.); \\ Tel.: +55-012-3947-6882 (N.G.); +55-012-3947-5942 (R.P.)
}

Received: 29 May 2018; Accepted: 27 June 2018; Published: 30 June 2018

\begin{abstract}
This article reports a novel and efficient method to synthesize graphene using a thermal decomposition process. In this method, silicon carbide (SiC) thin films grown on $\mathrm{Si}(100)$ wafers with an AlN buffer layer were used as substrates. $\mathrm{CO}_{2}$ laser beam heating, without vacuum or controlled atmosphere, was applied for SiC thermal decomposition. The physical, chemical, morphological, and electrical properties of the laser-produced graphene were investigated for different laser energy densities. The results demonstrate that graphene was produced in the form of small islands with quality, density, and properties depending on the applied laser energy density. Furthermore, the produced graphene exhibited a sheet resistance characteristic similar to graphene grown on mono-crystalline $\mathrm{SiC}$ wafers, which indicates its potential for electronic device applications.
\end{abstract}

Keywords: graphene synthesis; silicon carbide; thin film; high-power impulse magnetron sputtering; thermal decomposition; electronic devices

\section{Introduction}

Nowadays, the synthesis of high-quality graphene has been the focus of several researchers due to the great potential applications of this material in electronic devices, sensors and flexible displays [1].

Among the graphene synthesis methods, the thermal decomposition processes have been successfully used to grow graphene layers on silicon carbide ( $\mathrm{SiC}$ ) [2-5]. In general, these studies show the use of $\mathrm{SiC}$ wafers as substrates to be decomposed by heating, using an induction furnace at vacuum or at atmospheric pressure with an inert gas flow [6-10]. The kinetics of graphene formation and properties, such as structure and morphology, have been shown to be dependent on the reactor pressure, type of gas atmosphere, orientation, and face termination of the SiC wafer [10-12].

Most recently, the use of a laser beam as a heating source for graphene formation from $\mathrm{SiC}$ has been reported [13-15]. The focus of these studies was to investigate the growth of graphene on the Siand/or C-face terminations of SiC wafers. Perrone et al. used a near infrared Nd:YVO $(1064 \mathrm{~nm})$ laser to promote the heating of the SiC surface [13]. They reported the possible presence of graphene when this process was performed using argon gas flow, or in a vacuum at a pressure of $10^{-5}$ Torr. Using an 
ultra-high vacuum (UHV), only a disordered graphite phase was observed [13]. Lee et al., using an UV laser $(248 \mathrm{~nm})$, noticed not only that it is possible to grow epitaxial graphene (EG) from Si-terminated $\mathrm{SiC}$ (0001), but also pointed out that EG has a structure comparable to thermally-grown graphene under UHV using the same substrate [14]. Unlike the previous two studies, Yannopoulos et al. obtained graphene on $\mathrm{SiC}$ without the use of a vacuum environment or pre-treatment of the $\mathrm{SiC}$ substrate [15]. In their work, a carbon dioxide $\left(\mathrm{CO}_{2}\right)$ laser beam was used as the heating source, and the argon gas flow at atmospheric pressure was applied to form layers of EG. An advantage of using a $\mathrm{CO}_{2}$ laser is the cooling effect during pulsing, and the possibility of writing graphene patterns on $\mathrm{SiC}$, which eliminates the lithographic step [15]. Nevertheless, the aforementioned studies and their processes have a serious drawback - the use of high-cost $\mathrm{SiC}$ wafers as a substrate [16,17].

In another recent study, Galvão et al. reported on the growth of graphene layers on a low cost polycrystalline $\mathrm{SiC}$ substrate obtained from powder metallurgy using a $\mathrm{CO}_{2}$ laser beam [18]. Although the graphene obtained may be applied in several areas, this SiC substrate is not ideal for microelectronic applications. In order to improve the quality of the graphene samples without a significant increase in production costs, we explored the use of $\mathrm{SiC}$ thin films as substrates in combination with the $\mathrm{CO}_{2}$ laser beam heating technique for $\mathrm{EG}$ growth. Herein, $\mathrm{SiC}$ thin films were grown by high-power impulse magnetron sputtering (HiPIMS) on Si substrates covered with an aluminum nitride (AlN) buffer layer. To the best of our knowledge, the formation of graphene from $\mathrm{SiC}$ thin films grown on $\mathrm{AlN} / \mathrm{Si}$ substrates using a $\mathrm{CO}_{2}$ laser beam has not yet been reported in the literature [19]. The growth of crystalline $\mathrm{SiC}$ films directly onto silicon substrates is known to be difficult due to the large thermal stress between these materials. The literature shows that extensive effort has been devoted to reducing this problem, and that using the AlN buffer layer is a good choice [20-22]. The role of the AlN buffer layer is to allow the growth of a high-quality $\mathrm{SiC}$ film with a lower density of defects. Subsequently, high-quality graphene can be obtained by thermal decomposition of the SiC film. The growth of graphene on AlN buffer could be important in the development of new electronic device applications, such as high frequency resonators [23]. Furthermore, there is a growing interest in the integration of graphene into wide bandgap semiconductors for various applications [24].

In this work, different levels of laser energy density were applied during SiC thermal decomposition, and the chemical properties and quality of the graphene were evaluated using Raman spectroscopy. Moreover, to further understand the material characteristics, morphological and electrical measurements were performed using atomic force microscopy (AFM) and the four points probe method, respectively.

\section{Materials and Methods}

\subsection{SiC Thin Film Growth}

$\mathrm{SiC}$ thin films were deposited by HiPIMS on pieces of polished p-type $\mathrm{Si}(100)$ wafer covered with AlN buffer in a high-vacuum chamber with a background pressure of $6 \times 10^{-6}$ Torr. More details of the magnetron sputtering system can be found elsewhere $[25,26]$. The working pressure of the argon gas $(99.999 \%)$ was maintained at $3 \times 10^{-3}$ Torr for a corresponding flow rate of $20 \mathrm{sccm}$. A high-purity $\mathrm{SiC}$ (99.5\%, Kurt J. Lesker Company, Jefferson Hills, PA, USA) target with a 4 inch diameter was used. The sputtering reactor was powered by a HiPIMS power supply (Solvix $\mathrm{HIP}^{3} 5 \mathrm{~kW}$ ) with an applied power of $200 \mathrm{~W}$ and duty cycle of $5 \%$. The target-substrate distance was approximately $65 \mathrm{~mm}$ and the deposition was performed for $10 \mathrm{~min}$. The substrate holder was in a floating potential. Before starting the $\mathrm{SiC}$ deposition, a pre-sputtering period $(10 \mathrm{~min}$ at $200 \mathrm{~W})$ was performed to remove contamination from the target surface. The obtained $\mathrm{SiC}$ film on the AlN/Si substrate had an average thickness of $240 \mathrm{~nm}$.

The AlN buffer layer was grown on the $\mathrm{Si}(100)$ substrate using HiPIMS at Institut des Matériaux Jean Rouxel in Nantes University. More details can be found elsewhere $[27,28]$. The AlN film on the Si substrate had an average thickness of $1300 \mathrm{~nm}$, and the main crystallographic orientation was (002). 


\subsection{SiC Sublimation by $\mathrm{CO}_{2}$ Laser Heating}

Heating of the $\mathrm{SiC}$ thin film was carried out using a $\mathrm{CO}_{2}$ laser (Synrad Evolution-125) with a beam diameter of $200 \mu \mathrm{m}$, which emits infrared laser radiation at a wavelength band of $10.6 \mu \mathrm{m}$. The samples were positioned $5 \mathrm{~mm}$ below the laser focal point (see schematic diagram of the laser irradiation process in [18]). For all processes, a beam overlap of $50 \%$ was used. Three different laser scanning velocity rates were used: 2300,2500 and $2600 \mathrm{~mm} \mathrm{~s}^{-1}$. For all conditions, the laser power applied was $50 \mathrm{~W}$, which corresponded to $40 \%$ of the overall power. The entire process occurred under ambient atmosphere and pressure conditions. The energy densities of each scanning velocity were calculated and are shown in Table 1. In this investigation, the energy densities were between 127-145 J $\mathrm{cm}^{-2}$, whereas in previous studies, the values were between 132-200 $\mathrm{J} \mathrm{cm}^{-2}$ [18]. A lower energy density range was chosen because the properties of the synthesized graphene at higher laser energy densities did not present any significant difference in comparison with samples produced with lower energy densities [18].

Table 1. Scanning velocities and energy densities applied for each condition.

\begin{tabular}{cccc}
\hline & Condition 1 (C1) & Condition 2 (C2) & Condition 3 (C3) \\
\hline Scanning velocity $\left(\mathbf{m m ~ s}^{-\mathbf{1}}\right)$ & 2300 & 2500 & 2600 \\
Energy density $\left(\mathrm{J} \mathrm{cm}^{-\mathbf{2}}\right)$ & 145.25 & 136.95 & 127.69 \\
\hline
\end{tabular}

\subsection{Material Characterization}

The structure of the as-deposited $\mathrm{SiC}$ films was investigated using Grazing Incidence X-ray Diffraction (GIXRD) with an incidence angle $(\omega)$ of $0.3^{\circ}$ operated with a PANalytical X'pert Pro x-ray diffractometer (Almelo, the Netherlands) with $\mathrm{CuK} \alpha$ radiation.

Raman analyses were performed using a Horiba Raman microprobe system (LabRAM HR Evolution, Horiba, Kyoto, Japan) equipped with an argon ion laser (514.5 nm). Raman spectra of the $\mathrm{SiC}$ and graphene samples were obtained at room temperature in the range of $200-1100 \mathrm{~cm}^{-1}$ and 1200-2900 $\mathrm{cm}^{-1}$, respectively. The Raman spectral imaging (or Raman mapping) were obtained by focusing on the main characteristic bands (or peaks) of graphene. The type of defect present in the graphene film was inferred according to Eckmann et al. [29], which reported on a relationship between the intensity (height) of the ID and ID' peaks with the type of defect present in the graphene sample. The maximum ID/ID' ratio $(\sim 13)$ would correspond to $\mathrm{sp}^{3}$-defects, $(\sim 7)$ for vacancy-like defects and, $(\sim 3.5)$ for boundary defects [29]. In this work, the $\mathrm{D}^{\prime}$ peak is merged with the G peak. To determine the intensity of the $\mathrm{D}^{\prime}$ peak, a Lorentzian double peaks function fitting was applied to each Raman spectrum.

The surface morphology was investigated by atomic force microscopy (Veeco Instruments Inc, Plainview, NY, USA) (AFM Veeco Multimode with a Nanoscope V control station). The tapping mode was used for all samples except for sample $\mathrm{C} 2$, where contact mode was applied because it provided images with better resolutions.

\section{Results and Discussion}

\subsection{SiC Thin Film Structure}

In the literature, there is only one report of $\mathrm{SiC}$ growth on a $\mathrm{Si}$ substrate using HiPIMS [30]. However, due to the large lattice mismatch between $\mathrm{SiC}$ and $\mathrm{Si}(\sim 20 \%)$, the grown film exhibited amorphous characteristics and a high residual stress [28,30]. To reduce these effects, several studies have demonstrated that using a sacrificial layer (buffer layer) on the $\mathrm{Si}$ substrate before the deposition of $\mathrm{SiC}$ is an effective alternative. In this work, we chose to use AlN buffer, which presents a mismatching in the lattice constant of less than $1 \%$ compared to SiC. Figure 1 shows the GIXRD spectrum of the $\mathrm{SiC}$ thin film grown on $\mathrm{AlN} / \mathrm{Si}(100)$ substrate. As expected, the identified peaks reveal the polycrystalline nature of the SiC. 
In addition, the orientations of $\mathrm{SiC}$ indicated in the GIXRD spectrum agree with some studies in the literature [31-33]. We found that the peaks of the $\mathrm{SiC}$ matched well with those of $\alpha-\mathrm{SiC}(6 \mathrm{H}-\mathrm{SiC})$, however, it can be not excluded that $\beta-\mathrm{SiC}(3 \mathrm{C}-\mathrm{SiC})$ exists.

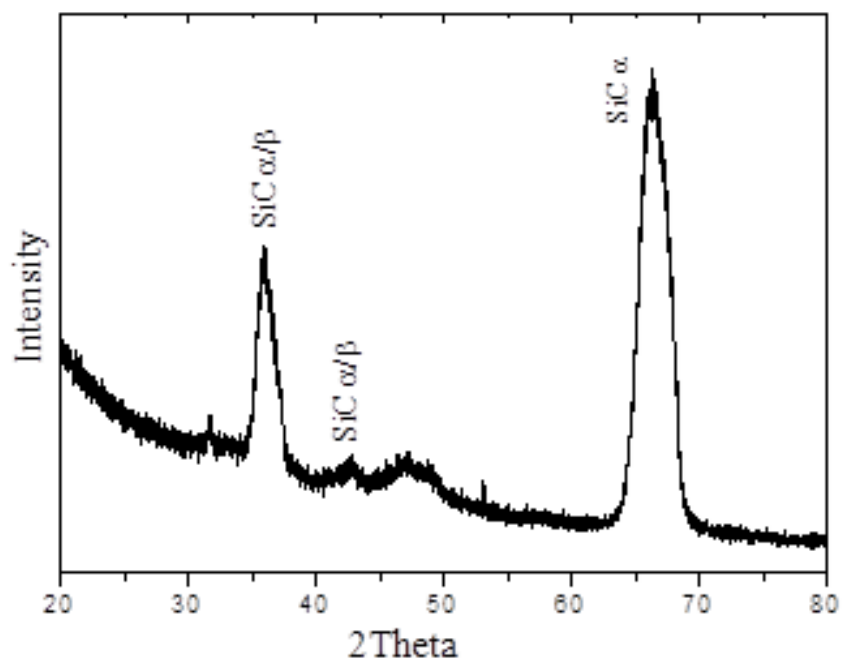

Figure 1. Grazing incidence x-ray diffraction spectrum of $\mathrm{SiC}$ film grown on $\mathrm{AlN} / \mathrm{Si}(100)$ substrate.

\subsection{Graphene Characterization}

Raman spectroscopy is a very useful technique to obtain important information about inherent features of carbon materials, such as graphene [34-37]. The Raman spectra of graphene contains three main in-plane vibrational bands: (i) G-band $\left(\sim 1584 \mathrm{~cm}^{-1}\right)$, corresponding to the doubly degenerate $\mathrm{E}_{2 \mathrm{~g}}$ phonon mode at the Brillouin zone center; (ii) D-band $\left(1200-1400 \mathrm{~cm}^{-1}\right)$, that arises from TO phonons around the K point and requires a defect for its activation; and (iii) 2D-band (2400-2800 cm${ }^{-1}$ ), which is the second order of the D-band and has been widely used to evaluate the number of layers and structural quality of graphene $[34,37]$.

Figure 2 shows the Raman spectra of each $\mathrm{SiC}$ sample that was laser treated. In addition, the Raman spectra of the unexposed $\mathrm{SiC}$ area are also presented. The presence of graphene $\mathrm{G}$ and 2D-bands and a significant number of defects (D-band) was observed (Figure 2b). Conversely, we noticed the absence of peaks related to the $\mathrm{Si}-\mathrm{C}$ band (Figure $2 \mathrm{a}$ ). The absence of the $\mathrm{Si}-\mathrm{C}$ bands can be an indication that, at this point, all the $\mathrm{SiC}$ was decomposed to form graphene. To verify the growth behavior and distribution of graphene in the treated sample, Raman mapping was performed (Figures 3 and 4).

The bright spots observed in the Raman maps (Figures 3 and 4), which are due to the presence of bands related to graphene, agree with the Raman spectra shown in Figure 2. The dark areas correspond to the absence of bands related to graphene. The mapping images also reveal that the graphene did not expand enough to cover the entire region of analysis, forming some "graphene islands". Furthermore, it is possible to observe a non-uniform distribution of higher intensity regions. This variation is probably related to the quality of the graphene. Several studies reported that the kinetics of graphene growth on the $\mathrm{Si}$ - or $\mathrm{C}$-face of $\mathrm{SiC}$ is distinct [3,36-40]. When $\mathrm{EG}$ is grown on the Si-face under UHV, the rate of sublimation is reduced, and therefore it is possible to control the growth of the graphene layers. This leads to the formation of a large and homogeneous monolayer [41,42].

When the C-face is considered, the growth rate is higher and its control is more difficult, which usually results in the formation of an inhomogeneous graphene layer $[3,38,39]$. However, Hass et al. reported that graphene grown on the $\mathrm{C}$-face of the $\mathrm{SiC}$ substrate in a RF furnace can be of exceptional quality [43]. This indicates that depending on the technique, it is possible to obtain high quality graphene on both faces. In our studies, graphene was grown on $\mathrm{SiC}$ thin film with undefined 
face-termination ( $\mathrm{Si}-\mathrm{C}$ face). Currently, there is a clear lack of studies reporting on the kinetics of graphene growth on $\mathrm{SiC}$ thin films using thermal decomposition by $\mathrm{CO}_{2}$ laser heating. Thus, according to the behavior observed by Raman mapping, and considering that the $\mathrm{SiC}$ film is polycrystalline and contains some amorphous areas, it is possible to presume that graphene was grown on both $\mathrm{Si}-\mathrm{C}$ face terminations. Growth on these two possible faces can result in graphene regions with a high defect concentration and different layers. In addition, the laser heating may have also influenced the growth and quality of the graphene. As obtained by Galvão et al. [18], the limited growth of graphene and non-dissociation of $\mathrm{SiC}$ in some regions of the material may have been influenced by the heat transfer along and across the heterogeneous surface. Inhomogeneities on the surface cause a non-uniform temperature distribution. A detailed Raman analysis performed on sample $\mathrm{C} 2$ revealed that the dark areas on the maps are composed of $\mathrm{SiC}$ films that did not get enough energy to dissociate and form graphene; however, crystallization started to take place instead, which can be verified by the well-defined $\mathrm{SiC}$ peak showed in Figure 5.

Finally, regarding the quality of graphene, the type of defects present in the sample were determined from the ID/ID' that was calculated from the Raman spectrum, collected at five random points of each sample. The values of the ID/ID' found were $3.7 \pm 1.0,4.1 \pm 0.5$ and $3.7 \pm 0.7$ for the samples C1, C2 and C3 respectively. According to Reference [18], these results indicate the presence of boundary defects.

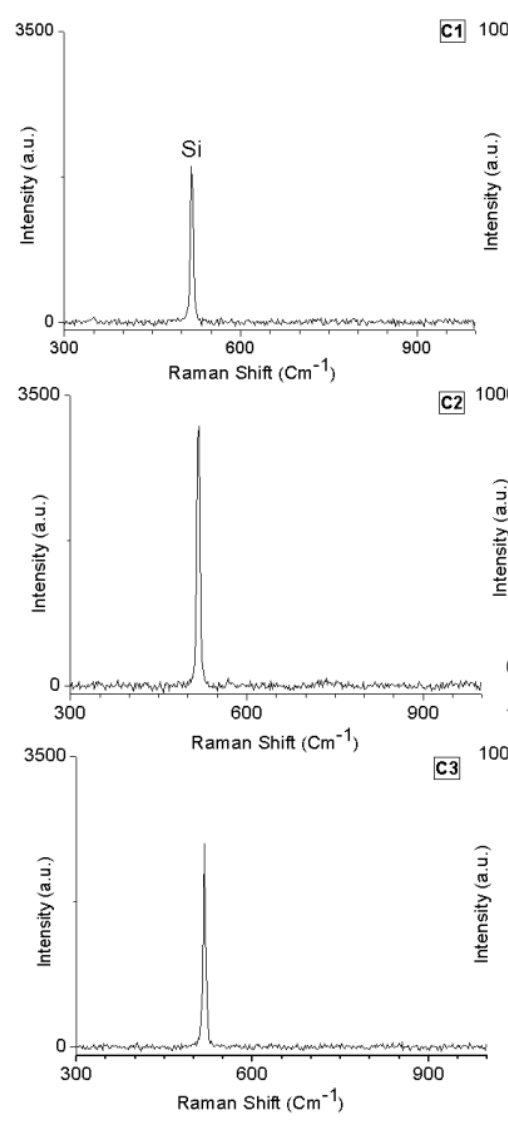

(a)

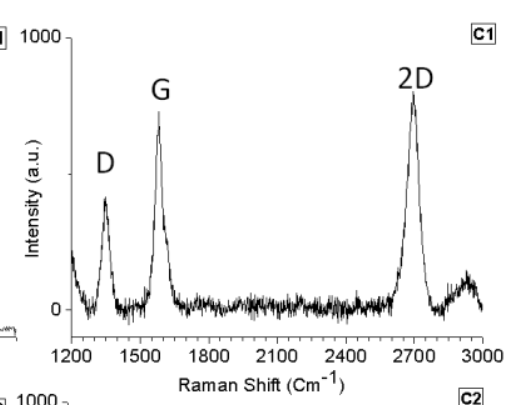

C2.
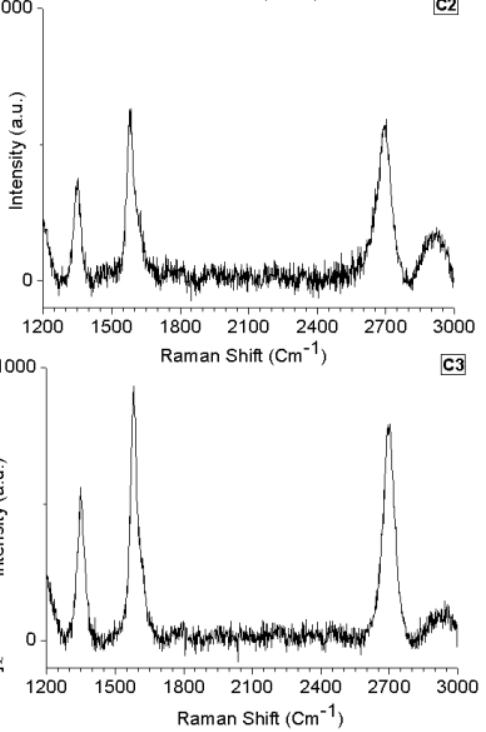

(b)

Figure 2. Raman spectra of the samples C1, C2 and C3: (a) scanning in the SiC area (column A); (b) scanning in the graphene area (column B). 


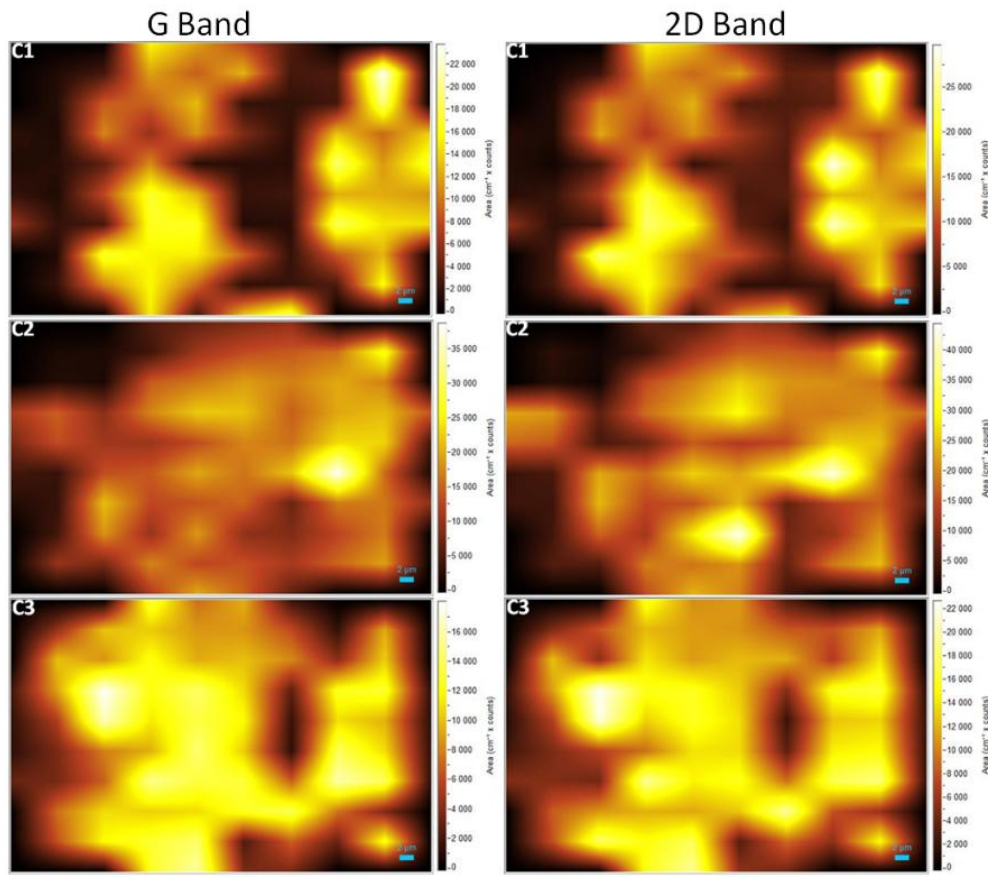

Figure 3. Raman mapping of the samples corresponding to $G$ and $2 D$ bands.
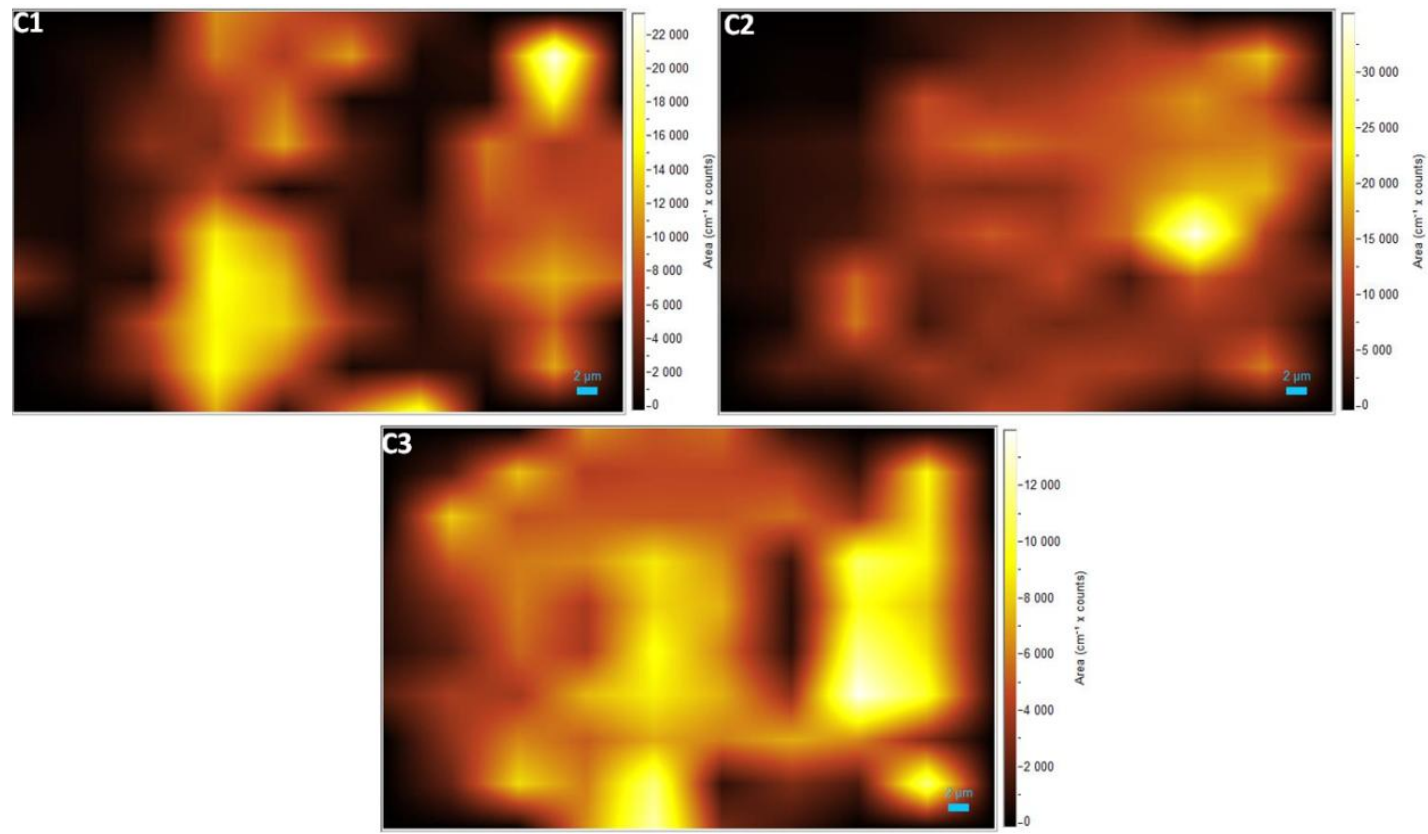

Figure 4. Raman mapping of the samples corresponding to D band. 


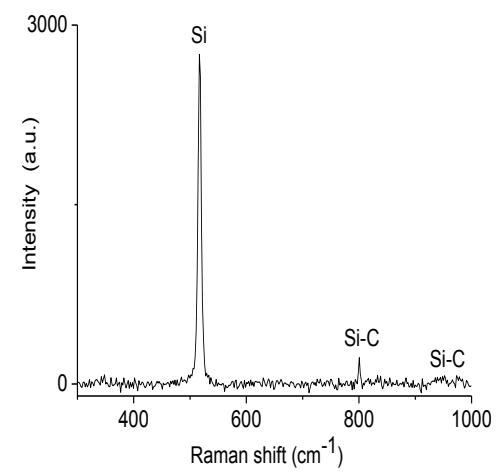

(a)

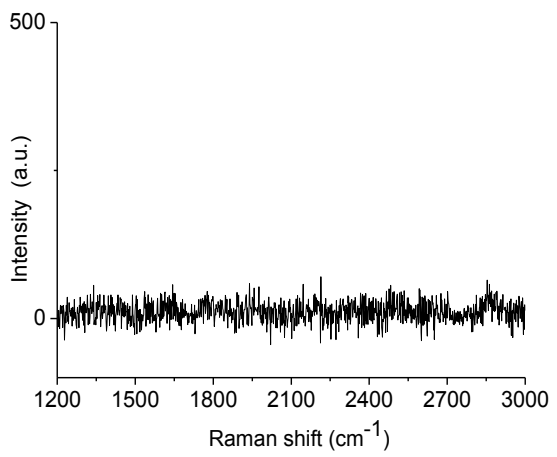

(b)

Figure 5. Raman spectra of the dark areas for C2 sample: (a) scanning in the SiC range (column A); (b) scanning in the graphene range (column B).

\subsection{Sheet Resistance and Morphology of SiC Thin Film and Graphene Layers}

As graphene is a material of great interest for electronic device applications, we have also analyzed the sheet resistance for each sample produced by the developed method (Table 2). In all conditions, the sheet resistance is lower than the sheet resistance of $\mathrm{SiC}$, but only the $\mathrm{C} 2$ sample presented properties consistent with graphene. The high sheet resistance presented by $\mathrm{C} 1$ and $\mathrm{C} 3$ may have occurred because the islands of graphene produced are small and not interconnected. Both Raman maps and AFM surface morphology images endorse this fact.

Table 2. Sheet resistance of SiC thin film and graphene inferred by the four points probe method.

\begin{tabular}{ccccc}
\hline Sample & C1 & C2 & C3 & SiC $^{\mathbf{1}}$ \\
\hline Sheet resistance $(\Omega / \square)$ & 30,900 & 26 & 29,320 & 60,000 \\
\hline
\end{tabular}

${ }^{1}$ Reference measurement made on $\mathrm{SiC}$ film substrate.

Before analyzing the surface morphology of the treated samples, it was important to verify the morphology of the SiC surface. Figure 6 shows the AFM images of the surface of the SiC films and the AlN buffer layer before laser treatment. As shown, the SiC film follows the morphology of the AlN layer with grains less than $100 \mathrm{~nm}$. These results indicate high quality SiC and AlN thin films.
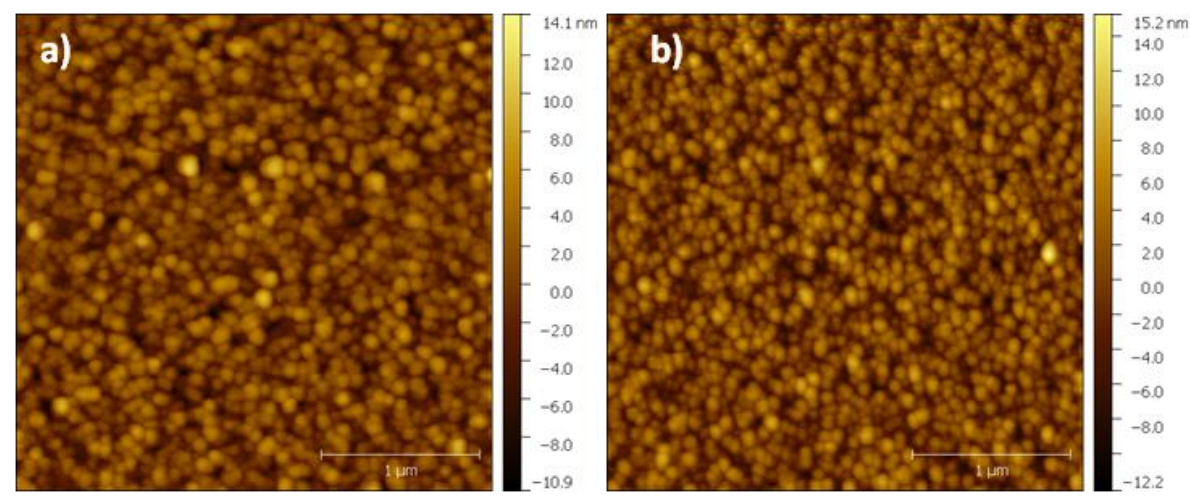

Figure 6. Atomic force microscopy images of $\mathrm{SiC}(\mathbf{a})$ and $\mathrm{AlN}$ (b) films.

Figure 7 shows the surface morphology of the samples C1, C2 and C3. For samples C1 and C3 (Figure 7a,b), it is only possible to observe small isolated graphene islands. On the other hand, for sample C2 (Figure 7c,d), the graphene layers are larger and well distributed across the surface 
area compared to $\mathrm{C} 1$ and $\mathrm{C} 3$. The growth of the islands can be visualized in the profile of Figure $7 \mathrm{~d}$ (sample C2), where stacking of the multilayers can be easily perceived. This result indicates that even a small difference in the energy density of the $\mathrm{CO}_{2}$ laser has a strong influence on the quality of the graphene grown on $\mathrm{SiC}$ film, which allows for the control of up to three orders of magnitude of material resistivity.

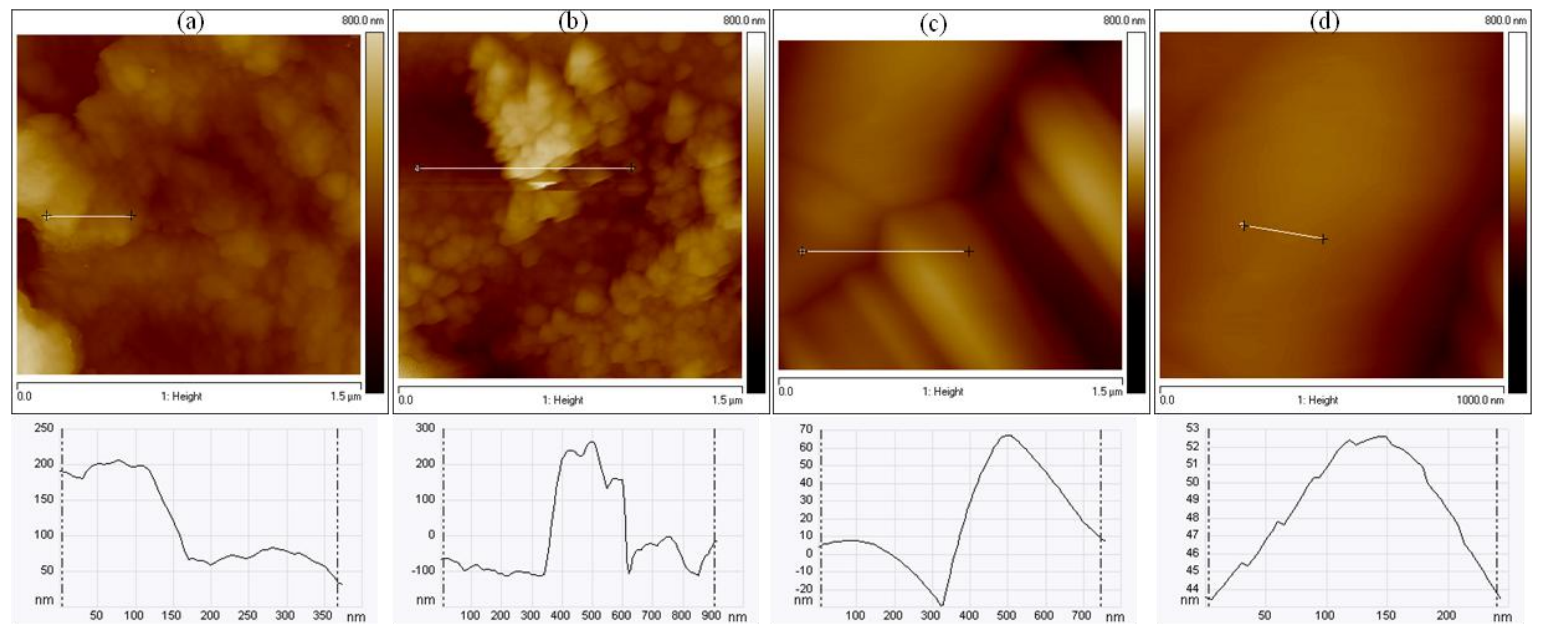

Figure 7. Atomic force microscopy images of samples C1 (a); C3 (b); and C2 (c,d). White line = profile traced to check the stacking of islands; result is shown in the chart below each image.

\section{Conclusions}

For the first time, we approached a feasible route for graphene growth based on the thermal decomposition of polycrystalline SiC thin films deposited by HiPIMS on AlN/Si substrates. For this purpose, we used $\mathrm{CO}_{2}$ laser beam heating without vacuum or controlled atmosphere. Raman mapping, along with AFM measurements, revealed the formation of islands of graphene on the SiC surfaces. The quality and density of the graphene islands was shown to be strongly dependent on the energy density of the laser process. It was observed that an energy density of the order of $137 \mathrm{~J} \mathrm{~cm}^{-2}$ allowed for obtaining interconnected graphene layers with some defects along the surface, resulting in a sheet resistance characteristic of graphene grown on pure crystal SiC wafer. Conversely, when the energy density was increased to $145 \mathrm{~J} \mathrm{~cm}^{-2}$, the density of the defects was considerably reduced. Finally, the results of this work demonstrate the feasibility of using the laser beam technique as a heating source for graphene formation on $\mathrm{SiC}$ thin films. This gives rise to new possibilities to explore the development of graphene layers on different substrates using the same methodology proposed here, which is a desirable situation for making different microelectronic and microelectromechanical systems (MEMS) devices. Given that the microfabrication processes are already well established for silicon wafers, there are still open issues related to $\mathrm{SiC}$ bulk etching.

Author Contributions: N.G., G.V., R.P., J.M., M.G. and J.C. provide the investigation and methodology, N.G., R.P., M.F., B.R., A.D. and H.M. write the original draft.

Funding: This work was supported by the Brazilian funding agencies: Coordenação de Aperfeiçoamento de Pessoal de Nível Superior (CAPES), grants No. 23038.005802/2014-98 and No. 88881.064970/2014-01, Conselho Nacional de Desenvolvimento Científico e Tecnológico (CNPq), grants No. 473043/2012 and 301982/2015-5, and Fundação de Amparo à Pesquisa do Estado de São Paulo (FAPESP), grants No. 2014/18139-8, 2018/01265-1, 2017/18826-3 and (FAPESP/CNPq/PRONEX) 2011/50773-0.

Acknowledgments: We gratefully acknowledge the Associate Laboratory of Sensors and Materials, Instituto Nacional de Pesquisas Espaciais (INPE), for Raman measurements.

Conflicts of Interest: The authors declare no conflict of interest. 


\section{References}

1. Tu, R.; Liang, Y.; Zhang, C.; Li, J.; Zhang, S.; Yang, M.; Li, Q.; Goto, T.; Zhang, L.; Shi, J.; et al. Fast Synthesis of High-Quality Large-area Graphene by Laser CVD. Appl. Surf. Sci. 2018, 445, 204-210. [CrossRef]

2. Hwang, J.; Kim, M.; Shields, V.B.; Spencer, M.G. CVD growth of SiC on sapphire substrate and graphene formation from the epitaxial SiC. J. Cryst. Growth 2013, 366, 26-30. [CrossRef]

3. Giusca, C.E.; Spencer, S.J.; Shard, A.G.; Yakimova, R.; Kazakova, O. Exploring graphene formation on the C-terminated face of SiC by structural, chemical and electrical methods. Carbon 2014, 69, 221-229. [CrossRef]

4. Ong, W.J.; Tok, E.S. Role of Si clusters in the phase transformation and formation of $(6 \times 6)$-ring structures on 6H-SiC(0001) as a function of temperature: An STM and XPS study. Phys. Rev. B 2006, 73, 045330. [CrossRef]

5. Gupta, B.; Notarianni, M.; Mishra, N.; Shafiei, M.; Iacopi, F.; Motta, N. Evolution of epitaxial graphene layers on $3 \mathrm{C} \mathrm{SiC/Si} \mathrm{(111)} \mathrm{as} \mathrm{a} \mathrm{function} \mathrm{of} \mathrm{annealing} \mathrm{temperature} \mathrm{in} \mathrm{UHV.} \mathrm{Carbon} \mathrm{2014,} \mathrm{68,} \mathrm{563-572.} \mathrm{[CrossRef]}$

6. Heer, W.A.; Berger, C.; Wu, X.; First, F.N.; Conrad, E.H.; Li, X.; Li, T.; Sprinkle, M.; Hass, J.; Sadowski, M.L.; et al. Epitaxial graphene. Solid State Commun. 2007, 143, 92-100. [CrossRef]

7. Röhrl, J.; Hundhausen, M.; Emtsev, K.V.; Seyller, T.; Graupner, R.; Ley, L. Raman spectra of epitaxial graphene on SiC(0001). Appl. Phys. Lett. 2008, 92, 201918. [CrossRef]

8. Tang, J.; Kang, C.Y.; Li, L.M.; Pan, H.B.; Yan, W.S.; Wei, S.Q.; Xu, P.S. Graphene grown on sapphire surface by using SiC buffer layer with SSMBE. Phys. Procedia 2012, 32, 880-884. [CrossRef]

9. Trabelsi, A.B.G.; Ouerghi, A.; Kusmartseva, O.E.; Kusmartsev, F.V.; Oueslati, M. Raman spectroscopy of four epitaxial graphene layers: Macro-island grown on $4 \mathrm{H}-\mathrm{SiC}$ substrate and an associated strain distribution. Thin Solid Films 2013, 539, 377-383. [CrossRef]

10. Norimatsu, W.; Kusunoki, M. Structural features of epitaxial graphene on $\mathrm{SiC}\{0001\}$ surfaces. J. Phys. D Appl. Phys. 2014, 47, 094017. [CrossRef]

11. Avouris, P.; Dimitrakopoulos, C. Graphene: Synthesis and application. Mater. Today. 2012, 15, 86-97. [CrossRef]

12. Yakimova, R.; Iakimov, T.; Yazdi, G.R.; Bouhafs, C.; Eriksson, J.; Zakharov, A.; Boosalis, A.; Schubert, M.; Darakchieva, V. Morphological and electronic properties of epitaxial graphene on SiC. Phys. B Condens. Matter 2014, 439, 54-59. [CrossRef]

13. Perrone, D.; Maccioni, G.; Chiolerio, A.; Marigorta, C.M.; Naretto, M.; Pandolfi, P.; Martino, P.; Ricciardi, C.; Chiodoni, A.; Celasco, E.; et al. Study on the possibility of graphene growth on $4 \mathrm{H}$-silicon carbide surfaces via laser processing. In Proceedings of the Fifth International WLT-Conference on Lasers in Manufacturing, Munich, Germany, 15-18 June 2009.

14. Lee, S.; Toney, M.F.; Ko, W.; Randel, J.C.; Jung, H.J.; Munakata, K.; Lu, J.; Geballe, T.H.; Beasley, M.R.; Sinclair, R.; et al. Laser-Synthesized Epitaxial Graphene. ACS Nano 2010, 12, 7524-7530. [CrossRef] [PubMed]

15. Yannopoulos, S.N.; Siokou, A.; Nasikas, N.K.; Dracopoulos, V.; Ravani, F.; Papatheodorou, G.N. $\mathrm{CO}_{2}$-Laser-Induced Growth of Epitaxial Graphene on 6H-SiC(0001). Adv. Funct. Mater. 2012, 22, 113-120. [CrossRef]

16. Fraga, M.A.; Pessoa, R.S.; Maciel, H.S.; Massi, M. Recent Developments on Silicon Carbide Thin Films for Piezoresistive Sensors Applications, Silicon Carbide-Materials, Processing and Applications in Electronic Devices; Mukherjee, M., Ed.; InTech: London, UK, 2011; Available online: http:/ / www.intechopen.com/books/silicon-carbide-materialsprocessing-and-applications-in-electronic-devices/recent-developments-on-silicon-carbide-thin-films-forpiezoresistive-sensors-applications (accessed on 10 May 2018).

17. Fraga, M.A.; Furlan, H.; Pessoa, R.S.; Rasia, L.A.; Mateus, C.F.R. Studies on $\mathrm{SiC}, \mathrm{DLC}$ and $\mathrm{TiO}_{2}$ thin films as piezoresistive sensor materials for high temperature application. Microsyst. Technol. 2012, 18, 1027-1033. [CrossRef]

18. Galvão, N.K.A.M.; Vasconcelos, G.; Santos, M.V.R.d.; Campos, T.M.B.; Pessoa, R.S.; Guerino, M.; Djouadi, M.A.; Maciel, H.S. Growth and Characterization of Graphene on Polycrystalline SiC Substrate Using Heating by $\mathrm{CO}_{2}$ Laser Beam. Mater. Res. 2016, 26, 1329-1334. [CrossRef]

19. Kumar, R.; Singh, R.K.; Singh, D.P.; Joanni, E.; Yadav, R.M.; Moshkalev, S.A. Laser-assisted synthesis, reduction and micro-patterning of graphene: Recent progress and applications. Coord. Chem. Rev. 2017, 342, 34-79. [CrossRef]

20. Jeong, J.; Jang, K.; Lee, H.S.; Chung, G.-S.; Kim, G. Raman scattering studies of polycrystalline 3C-SiC deposited on $\mathrm{SiO}_{2}$ and AlN thin films. Phys. B Condens. Matter 2009, 404, 7-10. [CrossRef] 
21. Huang, S.Y.; Xu, S.; Long, J.D.; Sun, Z.; Chen, T. Plasma-reactive SiC quantum dots on polycrystalline AlN films. Phys. Plasmas 2006, 13, 023506. [CrossRef]

22. Nakazawa, H.; Suemitsu, M. Low-temperature formation of an interfacial buffer layer using monomethylsilane for 3C-SiC/Si(100) heteroepitaxy. Appl. Phys. Lett. 2001, 79, 755-757. [CrossRef]

23. Qian, Z.; Hui, Y.; Liu, F.; Kang, S.; Kar, S.; Rinaldi, M. Graphene-aluminum nitride NEMS resonant infrared detector. Microsyst. Nanoeng. 2016, 2, 16026. [CrossRef]

24. Giannazzo, F.; Fisichella, G.; Greco, G.; la Magna, A.; Roccaforte, F.; Pecz, B.; Yakimova, R.; Dagher, R.; Michon, A.; Cordier, Y. Graphene integration with nitride semiconductors for high power and high frequency electronics. Phys. Status Solidi A 2017, 214, 1600460. [CrossRef]

25. Medeiros, H.S.; Pessoa, R.S.; Sagas, J.C.; Fraga, M.A.; Santos, L.V.; Maciel, H.S.; Massi, M.; Sobrinho, A.S.d.S.; da Costa, M.E.H.M. Effect of nitrogen content in amorphous $\mathrm{SiC}_{\mathrm{x}} \mathrm{N}_{\mathrm{y}} \mathrm{O}_{\mathrm{z}}$ thin films deposited by low temperature reactive magnetron co-sputtering technique. Surf. Coat. Technol. 2011, 206, 1787-1795. [CrossRef]

26. Medeiros, H.S.; Pessoa, R.S.; Sagás, J.C.; Fraga, M.A.; Santos, L.V.; Maciel, H.S.; Massi, M.; Sobrinho, A.S.d.S. $\mathrm{Si}_{\mathrm{x}} \mathrm{C}_{\mathrm{y}}$ Thin Films Deposited at Low Temperature by DC Dual Magnetron Sputtering: Effect of Power Supplied to Si and C Cathode Targets on Film Physicochemical Properties. Mater. Sci. Forum 2012, 717, 197-201. [CrossRef]

27. Belkerk, B.E.; Soussou, A.; Carette, M.; Djouadi, M.A.; Scudeller, Y. Structural-dependent thermal conductivity of aluminium nitride produced by reactive direct current magnetron sputtering. Appl. Phys. Lett. 2012, 101, 151908. [CrossRef]

28. Aissa, K.A.; Achour, A.; Camus, J.; le Brizoual, L.; Jouan, P.-Y.; Djouadi, M.-A. Comparison of the structural properties and residual stress of AlN films deposited by dc magnetron sputtering and high power impulse magnetron sputtering at different working pressures. Thin Solid Films 2014, 550, 264-267. [CrossRef]

29. Eckmann, A.; Felten, A.; Mishchenko, A.; Britnell, L.; Krupke, R.; Novoselov, K.S.; Casiraghi, C. Probing the Nature of Defects in Graphene by Raman Spectroscopy. Nano Lett. 2012, 12, 3925-3930. [CrossRef] [PubMed]

30. Leal, G.; Campos, T.M.B.; Sobrinho, A.S.d.; Pessoa, R.S.; Maciel, H.S.; Massi, M. Characterization of SiC thin films deposited by HiPIMS. Mater. Res. 2014, 17, 472-476. [CrossRef]

31. Li, W.; Yuan, J.; Lin, Y.; Yao, S.; Ren, Z.; Wang, H.; Wang, M.; Bai, J. The controlled formation of hybrid structures of multi-walled carbon nanotubes on $\mathrm{SiC}$ plate-like particles and their synergetic effect as a filler in poly(vinylidene fluoride) based composites. Carbon 2013, 51, 355-364. [CrossRef]

32. Raju, K.; Yu, H.W.; Park, J.-Y.; Yoo, D.H. Fabrication of SiCf/SiC composites by alternating current electrophoretic deposition (AC-EPD) and hot pressing. J. Eur. Ceram. Soc. 2015, 35, 503-511. [CrossRef]

33. Kim, K.J.; Kim, M.H.; Kim, Y.-W. Highly Conductive p-Type Zinc blende SiC Thin Films Fabricated on Silicon Substrates by Magnetron Sputtering. J. Am. Ceram. Soc. 2015, 98, 3663-3665. [CrossRef]

34. Calizo, I.; Bejenari, I.; Rahman, M.; Liu, G.; Balandinc, A.A. Ultraviolet Raman microscopy of single and multilayer grapheme. J. Appl. Phys. 2009, 106, 043509. [CrossRef]

35. Cançado, L.G.; Takai, K.; Enoki, T. General equation for the determination of the crystallite size La of nanographite by Raman spectroscopy. Appl. Phys. Lett. 2006, 88, 163-166. [CrossRef]

36. Pimenta, M.A.; Dresselhaus, G.; Dresselhaus, M.S.; Cançado, L.G.; Jorio, A.; Saito, R. Studying disorder in graphite-based systems by Raman spectroscopy. Phys. Chem. Chem. Phys. 2007, 9, 1276-1291. [CrossRef] [PubMed]

37. Malard, L.M.; Pimenta, M.A.; Dresselhaus, G.; Dresselhaus, M.S. Raman spectroscopy in graphene. Phys. Rep. 2009, 473, 51-87. [CrossRef]

38. Kumar, B.; Baraket, M.; Paillet, M.; Huntzinger, J.-R.; Tiberj, A.; Jansen, A.G.M.; Vila, L.; Cubuku, M.; Vergnaud, C.; Jamet, M.; et al. Growth protocols and characterization of epitaxial graphene on SiC elaborated in a graphite enclosure. Phys. E 2016, 75, 7-14. [CrossRef]

39. Escobedo-Cousin, E.; Vassilevski, K.; Hopf, T.; Wright, N.; O’Neill, A.; Horsfall, A.; Goss, J.; Cumpson, P. Local solid phase growth of few-layer graphene on silicon carbide from nickel silicide supersaturated with carbon. J. Appl. Phys. 2013, 113, 114309. [CrossRef]

40. Hass, J.; de Heer, W.A.; Conrad, E.H. The growth and morphology of epitaxial multilayer graphen. J. Phys. Condens. Matter 2008, 20, 323202. [CrossRef]

41. Tiberj, A.; Camara, N.; Godignon, P.; Camassel, J. Micro-Raman and micro-transmission imaging of epitaxial graphene grown on the $\mathrm{Si}$ and $\mathrm{C}$ faces of $6 \mathrm{H}-\mathrm{SiC}$. Nanoscale Res. Lett. 2011, 6, 478. [CrossRef] [PubMed] 
42. Jernigan, G.G.; VanMil, B.L.; Tedesco, J.L.; Tischler, J.G.; Glaser, E.R.; Davidson, A., III; Campbell, P.M.; Gaskill, D.K. Comparison of Epitaxial Graphene on Si-face and C-face 4H SiC Formed by Ultrahigh Vacuum and RF Furnace Production. Nano Lett. 2009, 9, 2605-2609. [CrossRef] [PubMed]

43. Hass, J.; Feng, R.; Li, T.; Li, X.; Zong, Z.; de Heer, W.A.; First, P.N.; Conrad, E.H. Highly ordered graphene for two dimensional electronics. Appl. Phys. Lett. 2006, 89, 143106. [CrossRef]

(C) 2018 by the authors. Licensee MDPI, Basel, Switzerland. This article is an open access article distributed under the terms and conditions of the Creative Commons Attribution (CC BY) license (http://creativecommons.org/licenses/by/4.0/). 